\title{
ARQUITECTURAS EMERGENTES: VIDEOMAPPING EN EL MUSEO
}

\section{EMERGING ARCHITEGTURES: VIDEOMAPPING IN THE MUSEUM}

\section{ALEJANDRO JIMÉNEZ L.}

Docente asociado y coordinador del área audiovisual de la carrera de artes visuales.

Facultad de Humanidades y Ciencias Sociales Pontificia Universidad Javeriana de Cali.

jalejandro@javerianacali.du.co

Cali, Valle del Cauca, Colombia

\section{LILIANA VERGARA Z.}

Docente tiempo completo. Directora de Investigación en la facultad de artes visuales y aplicadas

Facultad de artes visuales y aplicadas Instituto Departamental de Bellas Artes de Cali azulzambra@hotmail.com Cali, Valle del Cauca, Colombia
PALABRAS CLAVES

Arte contemporáneo, Arte digital,

Videomapping, Nuevos medios, Tecnologia,

Ciudad, Arquitecturas Emergentes
KEY WORDS

Contemporary art, Digital art,

VideoMapping, New media, Technology, City 


\section{Resumen}

El recurso digital ha transformado los modos de relacionarse, no sólo en lo social sino en las dinámicas mismas de representación. El Videomapping, como procedimiento técnico, es uno de mecanismos contemporáneos que estimulan las interrelaciones desde lo gráfico, lo audiovisual, lo multimedial, y lo digital en el arte; permitiendo interactuar con el público, como también, establecer experiencias artísticas en las cuales se abordan dimensiones de disertación entre Arte, Tecnología y Sociedad, categorías fundamentales en los análisis estéticos contemporáneos. Se establece el eje temático como la aproximación a la proyección en gran escala sobre fachadas arquitectónicas y su relación con la creación artística contemporánea, donde el propósito es reconocer como las Artes Visuales Contemporáneas, aplican recursos mediáticos y digitales para la creación de experiencias artísticas, haciendo referencia al arte público, al arte efímero, al arte espectáculo como categorías a ser observadas. Y de forma simultánea, se cuestiona sobre como se aproximan y se crean estas experiencias artísticas desde el Videomapping como recurso tecnológico y su aplicación real en la escena artística local, y en este caso en particular, a través de la obra "Arquitecturas Emergentes" (2015), la cual es considerada como la primera experiencia en videomapping, proyectada en un museo en Colombia, asumida como pieza artística; buscando comprender el impacto y la reflexión que este tipo de actividades presentadas a un público masivo, con la intensión de generar en los espectadores una experiencia sensible a través de la imagen, el color, el movimiento y el reconocimiento de imágenes que evocan los espacios arquitectónicos, y como se relaciona a través de los lugares icónicos, como el Museo La Tertulia de la ciudad de Cali.

\section{Abstract}

The digital resource has transformed the modes of interrelation, not only in the social but in the very dynamics of representation. VideoMapping, as a technical procedure, is one of contemporary mechanisms that stimulate the interrelationships from the graphic, the audiovisual, the multimedia, and the digital in art; allowing interacting with the public, as well as establishing artistic experiences in which dimensions of dissertation between Art, Technology and Society are addressed, fundamental categories in contemporary aesthetic analysis. Our thematic axis is established as the approach to the large-scale projection on architectural facades and its relationship with contemporary artistic creation, where the purpose is to recognize, as the Contemporary Visual Arts apply media and digital resources for the creation of artistic experiences, making reference to public art, ephemeral art, show art as categories to be observed. And simultaneously, it is questioned about how these artistic experiences are approached and created from VideoMapping as a technological resource and its real application in the local artistic scene, and in this case in particular, through the work "Emerging Architectures" ( 2015), which is considered the first experience in videomapping, projected in a museum in Colombia, assumed as an artistic piece, seeking to understand the impact and reflection that this type of activity activates in the mass public, with the intention of generating in viewers a sensitive experience through image, color, movement and image recognition that evoke the architectural spaces, and how it is related through the iconic places, such as the La Tertulia Museum in the city of Cali. 


\section{Introducción}

Partiendo de la premisa dada por Jackson Pollock, quien afirmaba que las nuevas necesidades del mundo moderno requieren nuevas técnicas, en la cual, los artistas han encontrado nuevas formas y medios para continuar con sus requerimientos expresivos: "cada edad encuentra su propia técnica" (Wigal, 2011) . En este sentido, las técnicas digitales han transformado los modos de la construcción de ciudad a partir de la interrelación social, a través de las dinámicas de representación y comunicación. De esta forma, las tecnologías digitales involucran la creación de diversas formas de representación, en múltiples formatos, que obliga la comprensión y aprehensión de los nuevos lenguajes formales; es apropiado asumir que la sociedad no es impactada por la tecnología (comprendido como una colisión entre dos fuerzas) sino mas bien influenciada, el instrumento por si mismo no tiene la capacidad de transformar la sociedad; es el entorno social quien lleva dinámicas propias de acuerdo a sus condicionantes económicos, sociales y políticos y es a estos condicionamientos a los que se adapta la tecnología, donde una polis creativa esta dispuesta a diagnosticar sus necesidades de representación y gestionar sus recursos icónicos y hacerlos prevalecer en su dimensión social e histórica.

\section{Objetivos}

\section{Principal}

Reflexionar sobre los mecanismos conceptuales, artísticos y técnicos del primer videomapping de carácter artístico realizado en Colombia: Arquitecturas Emergentes, proyectado el 27 de Enero del 2015 en el museo de arte La Tertulia de Cali.

\section{Particulares}

- Analizar y reflexionar sobre los principales elementos de construcción del arte contemporáneo en sus contextos de ciudad, espectador, espectáculo, público y tecnología.

- Determinar y discernir sobre el modelo de producción del videomapping Arquitecturas Emergentes, desde las dimensiones técnica, conceptual, narrativa y estética.

\section{Metodología}

Para la realización de esta investigación se parte de mecanismos metodológicos de la investigacióncreación, requiriendo un modelo empírico a la a aproximación del proceso creativo, que surge de un recurso experimental y exploratorio, en el cual se construye la base teórica que articula técnicas plásticas y características inherentes del arte digital; estableciendo puentes entre los escenarios del arte y la tecnología en la mira de un marco regional, que permite reflexionar acerca del espacio, la ciudad, el individuo y la imagen digital. De igual manera, se procura favorecer la búsqueda de estrategias propias que posibiliten abordar un territorio en la investigación artística, enmarcada en la creación de una narrativa visual a través 
del Videomapping.

Se establecen parámetros tangibles en la identificación de los procesos de creación, en los que interviene lo artístico y lo tecnológico, para formular algunas relaciones entre el arte y la tecnología en el contexto local de Cali - Colombia, aplicando procedimientos propios de la creación artística, como también reconociendo los medios del recurso tecnológico.

Desde el proceso creativo/conceptual, se realiza una aproximación en principio de analogía (lo que ya conozco, lo que ya he visto), pasando posteriormente a procesos aleatorios que permiten asociaciones casuales, relaciones artificiales y procesos al azar en la construcción visual, un proceso de reflexión en la creación de una proyección pública en un espacio especifico de la ciudad; esta reflexión es marcada por el sentido crítico a diversos aspectos de asociación personal frente a problemáticas de la ciudad (arte, individuo, sociedad, ciudad, historia, espacio público, etc.), determinado por las pulsiones y reconocimientos de identidad dentro del entorno social, elementos que se desenmascaran al hacer participes al Museo como socio estratégico y eje fundamental de la exhibición.

De forma simultanea, se accede a la experimentación técnica, afrontando un proceso concreto de aproximación al medio digital, al proyector y al gran formato; exigiendo algunos pasos concretos como son: reconocimiento y profundización del software de mapeado, manipulación de texturas estáticas y dinámicas, mapeados de la arquitectura, análisis de superficies sobre las que se proyecta, enmascaramiento y proyección por capas, análisis bidimensional y tridimensional del espacio, reconocimiento y análisis de proyectores, aproximación a los mecanismo de captura de movimiento, realización de piezas audiovisuales y pruebas en objetos bidimensionales y tridimensionales, pruebas de función y ajustes; llegando finalmente a la proyección del "proyecto artístico / espectáculo audiovisual" frente a la ciudad.

Es importante considerar que tanto el procedimiento técnico como el de creación son mutuamente afectados, obligando a una verificación y retroalimentación constante en los distintos procedimientos realizados.

\section{La sociedad digital en el arte}

La relación con lo artístico, lo textual y lo social, ya no es soló sobre un soporte físico inmutable, por el contrario, el avance tecnológico ha introducido otros lenguajes; pero, no en función de la técnica, sino en las relaciones de poder del consumo de la imagen, las cuales comienzan a replantear temas de mayor complejidad como: ¿hacia dónde va la información en esta era de lo digital? ¿Por qué conceptos como interactividad, espacio público, experiencia estética, están demarcando el devenir del arte digital?

Estamos ante una estética laberinto. Los desarrollos tecnológicos y las estéticas digitales, multimediales, revelan una organización social con diferentes modos de expresión y de comunicación. Los individuos han transformado sus dinámicas de representación, con lo cual las rupturas en las dimensiones de tiempo y espacio esconden un actuar social y artístico 
diferenciado, caracterizado por otros hábitus, otras prácticas y otras rutinas de creación (Trujillo, 2012).

En este sentido, la relación entre creación y tecnología se inscribe en lo que Bourdieu (1972) caracteriza como campo, en el cual, dicho concepto es indisociable al de hábitus:

El principio de la acción histórica, la del artista, la del científico o la del gobernante, como también la del obrero o la del pequeño funcionario, no radica en un sujeto que enfrentaría a la sociedad como a un objeto constituido en la exterioridad. Dicho principio no radica ni en la conciencia ni en las cosas, sino en la relación entre dos estados de lo social, es decir, la historia objetivada en las cosas bajo forma de instituciones, y la historia encarnada en los cuerpos bajo la forma del sistema de disposiciones duraderas que llamo hábitus (p. 37-38)

Entretanto, para Giménez (1997, p.13):

El hábitus sería el resultado de la incorporación de las estructuras sociales mediante la "interiorización de la exterioridad", mientras que el campo sería el producto de la "exteriorización de la interioridad", es decir, materializaciones institucionales de un sistema de hábitus efectuadas en una fase precedente del proceso histórico-social.

Esta indagación se aborda desde la conciencia de hábitus y de campo, con lo cual se plantea el uso de los diferentes medios tecnológicos, específicamente a través del Videomapping llevado a la categoría de obra de representación y experiencia artística; asociando lo anteriormente expuesto: el hábitus, se propone comprender el entorno colombiano, el cual, de acuerdo a las dinámicas de colonización económica, lo que Slavoj Žižek plantea como la "autocolonización", al señalar que:

Hoy el capitalismo global entraña nuevamente una especie de "negación de la negación". En un principio (desde luego, ideal) el capitalismo se circunscribe a los confines del Estado-Nación y se ve acompañado del comercio internacional (el intercambio entre Estados-Naciones soberanos); luego sigue la relación de colonización, en la cual el país colonizador subordina y explota (económica, política y culturalmente) al país colonizado" (Zizek, 1998).

En este sentido, Colombia, al igual que la mayoría de los países de influencia neoliberal, es proclive a la espectacularidad de la imagen, al disfrute del entretenimiento y eventos masivos de la moda y el espectáculo, lugar habitual de las tecnologías de proyección en gran escala como el Videomapping, que implica elevados costes de ejecución y exhibición. Estas proyecciones en vivo, con adaptación a las estructuras arquitectónicas ya existentes, se han presentado principalmente en ciudades con mayores recursos económicos y técnicos en todo el mundo, presentado fundamentalmente como mecanismo de espectacularidad a la imagen proyectada, el publico masivo asiste a un evento promocional de grandes proporciones: inauguraciones de empresas, estaciones ferroviarias, edificios emblemáticos, fiestas populares, celebraciones institucionales, eventos navideños, reconocimientos sociales, actividades de la moda, objetos de consumo, y un gran etcétera asociado a la promoción y la publicidad. 
De igual forma, el videomapping ha hecho presencia en Colombia desde hace pocos años atrás, y al igual que el cinematógrafo en sus inicios, solo es referido como una atracción de las masas con escasa referencia en los medios de comunicación, que impide confrontar o descubrir las dimensiones reales del fenómeno del videomapping en el país, y debido a las condiciones mencionadas (altos costos y requerimientos técnicos), ha dejado a un lado, al menos por el momento, a ciudades de menor tamaño o capacidad económica o técnica. Así mismo, ciudades como Bogotá, Cali y Medellín se han vuelto recurrentes en la utilización de esta técnica en eventos promocionales y publicitarios. De esta "novedad" no se han librado edificios emblemáticos, con valor iconográfico en las ciudades: iglesias, estaciones de metro, edificaciones abandonadas, edificios institucionales, ministerios, alcaldías, y otras edificaciones en las que se incluyen centros de arte y museos, pero asociados a proyecciones de espectáculo y a los showbussines mencionados anteriormente y no como piezas pertenecientes a la esfera artística. Esa situación es afín al planteamiento que Gunning (1983) sobre la llegada del cine a la esfera artística a principios del s. XX.

Los escritos de los primeros vanguardistas del cine (futuristas, dadaístas y surrealistas) siguen un patrón similar al de Léger: entusiasmo por este nuevo medio y sus posibilidades, y desagrado por el modo en que se ha desarrollado, por su esclavitud a las formas artísticas tradicionales, en especial el teatro y la literatura. Esta fascinación por el potencial de un medio (y la fantasía correlativa de rescatar al cine de su esclavitud respecto de formas pasadas y ajenas) puede ser entendida desde numerosos puntos de vista. Gunning (1983)

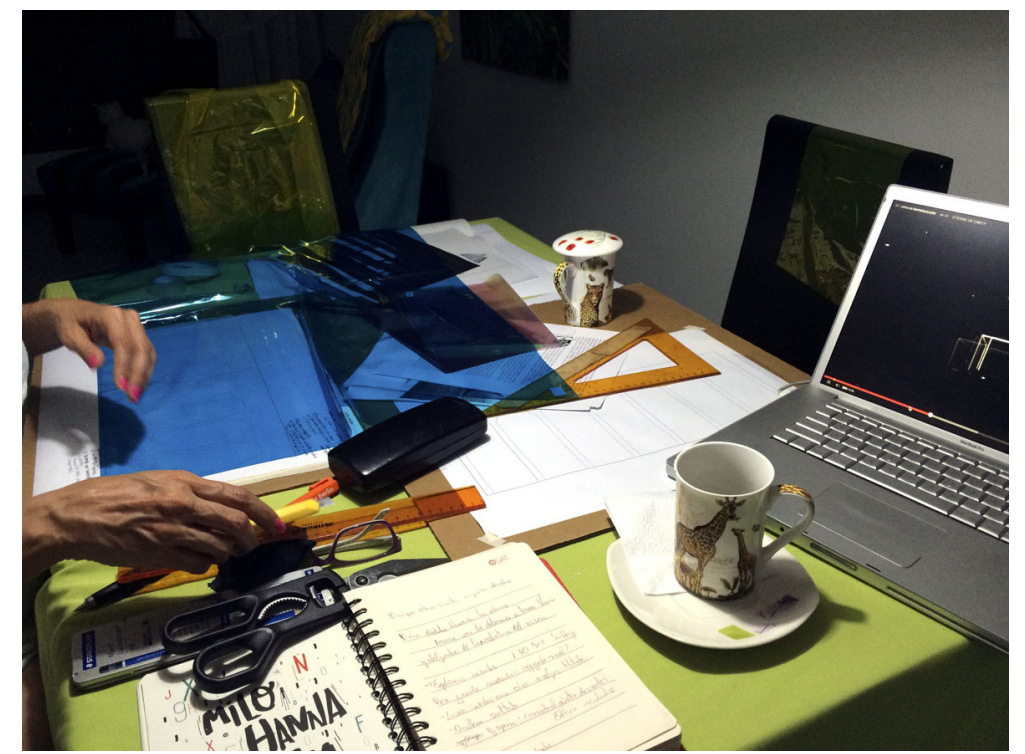

Imagen 1 - Procesos Iniciales en la conceptualización y creación del videomapping Arquitecturas Emergentes. Elaboración propia

Lo anterior implica, de una parte, explorar las herramientas técnicas y conceptuales en la creación de Videomapping, buscando involucrar el contexto que rodea la conformación de esas nuevas formas estéticas, gracias a las interrelaciones entre lo gráfico, lo audiovisual, lo multimedial y lo digital en el arte. De otra parte, es necesaria la pesquisa para establecer recursos en la creación artística contemporánea, abordando espacios históricos de Santiago de Cali que confronten la transformación de su espacio urbano y los comportamientos que suscita en los individuos. 
Mas allá de la dimensión espacial, el paisaje urbano se extiende en la forma en que la gente que lo habita lo comprende y se relaciona con el mundo material que le rodea, de esta forma las condiciones de apropiación de ese mundo son siempre contingentes, haciendo evidente que los paisajes culturales están siempre desordenados y en disputa. En Santiago de Cali, ciudad fundada en 1536 por el conquistador español Sebastián de Belalcázar, que la convierte en una de las ciudades mas antiguas de América, esa constituida por la complejidad de los intercambios culturales, donde la cotidianidad establece, como es lógico, una invisibilidad frente al intercambio o las tensiones en los recorridos de la transculturación, lo que implica una labor de traducción cultual y apropiación de lo cotidiano, que a fuerza de recorrer a diario, deja de verse. Paisajes demasiado públicos, demasiado ordinarios dejan de verse, una ciudad que ha arrasado con su patrimonio arquitectónico, dejando, como dice Habermas: el paisaje urbano, ya no es determinado por la arquitectura sino por el conjunto de sus avisos comerciales, (Satué, 2001), lo cual no es menos cierto en la capital Vallecaucana, dando cuenta de numerosas dinámicas de ciudad, de comercio, de diferencias sociales, de inmigración y trashumancia adaptado a productos culturales racionalizados y estandarizados. En esta aprehensión de lo cotidiano, el museo La Tertulia, construido en un recodo del rio que constituía un entorno de regocijo familiar popular, instaurando un edificio de cultura, que albergó por muchos años encuentros de gráfica y discusión panamericana del arte, reconstituyendo la necesaria cuestión anti hegemónica propia de años pasados; museo que da cabida hoy día a dispositivos sin frontera del mecanismo del arte contemporáneo, con instrumentalización tecnológica basadas en el arte y no en su origen, donde parafraseando a Malraux, se constituye el museo como "memoria viva" (Malraux, 1956) que trata de conservar los objetos que hablan de momentos históricos individuales o colectivos, como memoria útil para comprender el pasado con miras al futuro (Hernández, 1994), en este caso la desmaterialización del audiovisual proyectado, establece la ingravidez o intangibilidad del paradigma moderno.

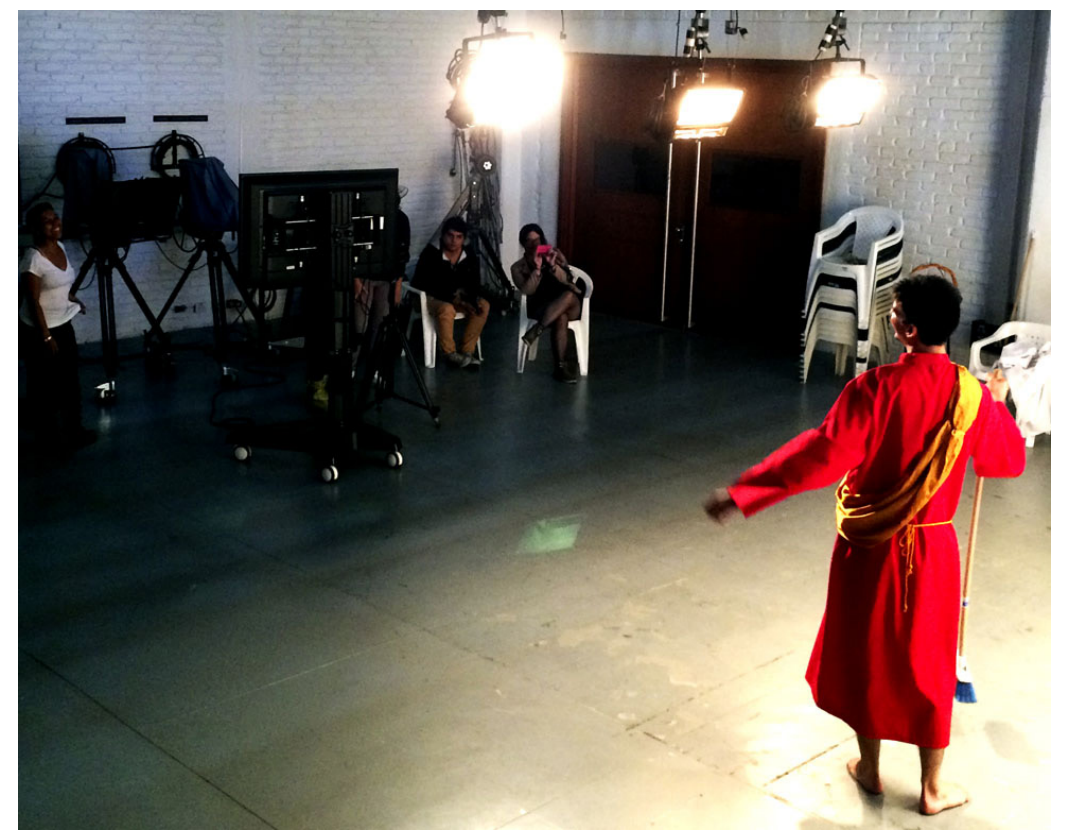

Imagen 2 - Reconocimiento de la diversidad cultural y religiosa. Imagen de captura de movimiento para técnica de rotoscopia. Imagen de elaboración propia. 
Adriana Gómez planteaba la dimensión Cyborg de los nuevos individuos que recorren la ciudad, el espacio publico mediado y recorrido por dispositivos que ayudan a ampliar los sentidos y las capacidades humanas, pero así mismo favorecen el aislamiento personal, dificultando el encuentro ciudadano.

Los mapas mentales para los nuevos cyborgs ya no tendrán que estar en su cabeza. Las extensiones electrónicas y los dispositivos manuales con mojones invisibles serán los sistemas de orientación que nos permitirán capturar y procesar el conocimiento para guiar nuestro movimiento... proponiendo una reflexión acerca del papel de la tecnología en la ampliación de los sentidos y como estas pueden modificar las relaciones corporales con los espacios de uso público en las ciudades. (Gómez, 2004. p. 27)

La vida de la modernidad liquida, parafraseando a Bauman (2005), establece con los objetos una fecha de caducidad, una utilidad limitada por el tiempo. Convierte lo indispensable en rancio recuerdo, lo que pone en jaque las relaciones conceptuales entre tecnología y sociedad, en beneficio del consumo y del capital. Aquí es donde el arte contemporáneo entra como herramienta para discernir sobre la velocidad de la tecnología y sobre el tiempo; permitiendo la creación de obras efímeras, limitadas en el tiempo y en el espacio, las cuales serán absorbidas por un ejercicio cotidiano de fugacidad universal.

En este proceso, también se establecen conexiones con referentes históricos que permitieran encontrar una línea evolutiva con la captura y proyección en gran formato, como los cosmoramas y panoramas, el cine y sus precursores o Philosophical Toys, que promueven el estudio sobre el movimiento. En términos de Oubiña (2009), los juguetes filosóficos se encontraban "oscilando entre una mera curiosidad, a propósito de los efectos ópticos y una argumentación filosófica sobre el funcionamiento de la vista (...) fico de la ciudad de cali del espacio iconogrecanico umo y del capitalque introducen la problemática de la subjetivación de la mirada y la pregunta por la accesibilidad del momento presente en la representación".

El mecanismo del espectáculo propone una transformación técnica y conceptual sobre el público o campo social.

Como plantea Jiménez (2010):

Toda la inventiva técnica aplicada a la creación, ha buscado perfeccionar mecanismo preestablecidos, se hacen variaciones para mejorar una condición existente ... la última revolución para el medio audiovisual, se produjo con la aparición de ordenadores con capacidad para procesar inmensas cantidades de información, afectando la creación de efectos especiales, el proceso de postproducción, edición y mezclas de audio (p. 23). 


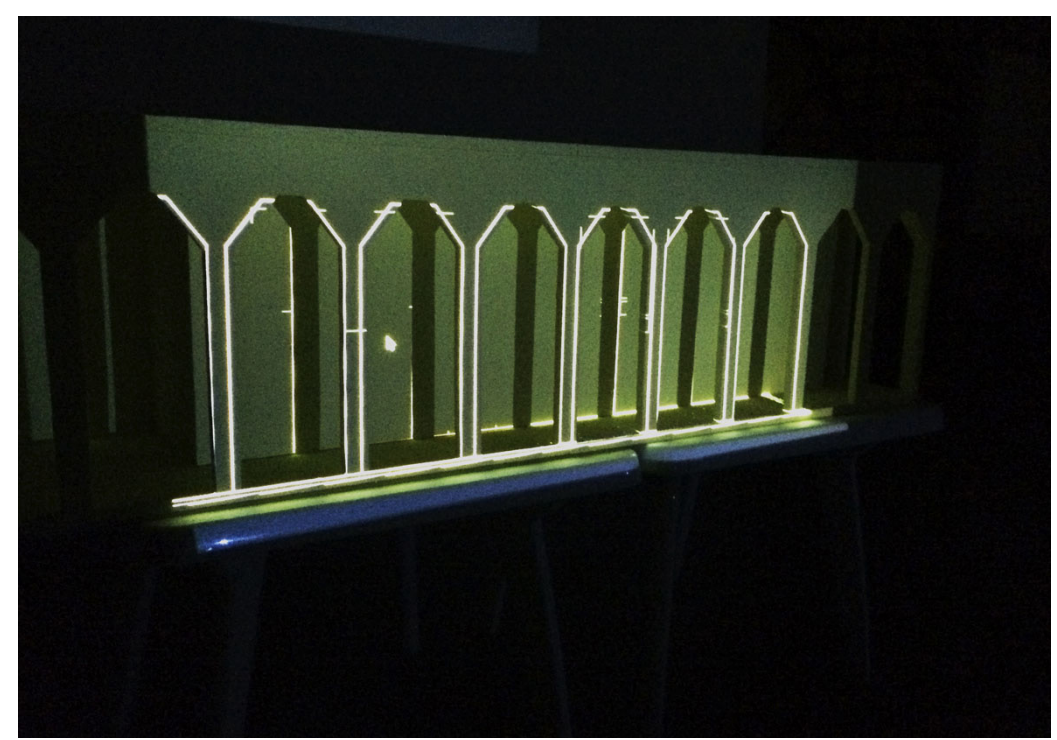

Imagen 3 - Pruebas de función de la imagen proyectada sobre maqueta a escala de la fachada del museo La Tertulia. Imagen de Elaboración propia.

Estos elementos juntos integran diversas dinámicas generadas entre el espectador y el creador, asumiendo los cambios en su mecanismo interno de creación y exhibición. En este sentido, se acudió al recurso del Videomapping, como una herramienta propia de las nuevas tecnologías. Recurso que integra elementos como el cine, la narración, la animación y la monumentalidad de la proyección, y da lugar al planteamiento de nuevas pantallas de proyección y de nuevos recursos para relacionarse con el público contemporáneo, que requiere mecanismos de participación activa; donde, aceptando la proposición de Lorena Rodríguez, "se establece una relación entre la propia imagen, el espacio expositivo y el espectador" (2011, p.169), convirtiendo las paredes exteriores del museo, de forma explicita, en una fusión del espacio de representación con el espacio de exhibición, lo cual es mas que evidente y necesario, en un ejercicio de videomapping, donde es requerida la relación absoluta del entorno espacio- temporal, ya no confrontando, sino intersectando el espacio interno de la imagen proyectada con el espacio externo que le rodea, a lo que el espectador se relaciona a través de

Una recepción físicamente activa, que rompe con la idea del punto de vista fijo y privilegiado, disminuyéndose la distancia con la imagen. Se introduce así una nueva temporalidad: junto con el tiempo de duración de la obra, entra en juego el tiempo de la recepción, que puede diferir del primero, pues el espectador se desplaza, entra y sale, se mueve libremente por el espacio expositivo convertido en espacio para la videografía. (Rodríguez, 2011. p.170)

Esta movilidad del espectador y su transformación en el tiempo de recepción lo convierte en participante, lo que en Arquitecturas Emergentes se manifestó por la condición efímera de su proyección, donde se realizaron cuatro proyecciones en una sola noche, el publico presente tenia la opción de cambiar de ubicación, desplazarse, distanciarse de los muros proyectados o acercarse cuanto quisiera, escuchar el sonido desde otro lugar sin ver la imagen, dialogar con los demás participantes y establecer relaciones de aproximación al museo que abrió las puertas a los visitantes de forma gratuita, lo que permitió convertir al espectador en un 
flâneur, que camina sin sentido, dejándose llevar por los estímulos de imágenes, espacios, objetos, sonidos, construyendo apropiaciones espaciales a través del devenir de los sentidos.

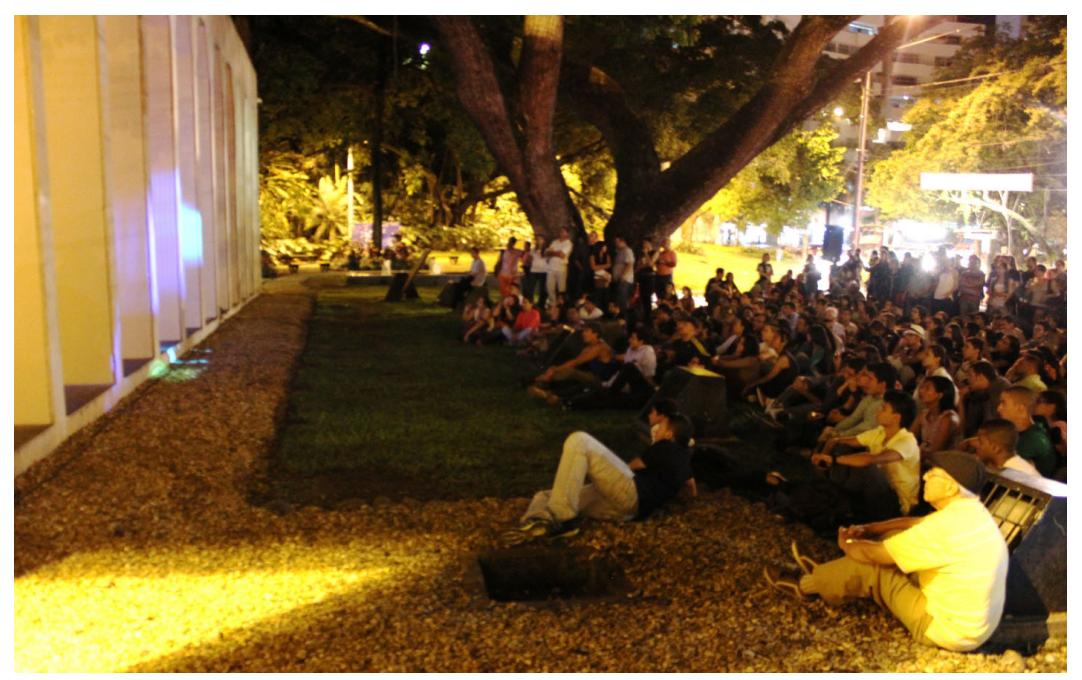

Imagen 4 - Publico durante la proyección del videomapping Arquitecturas Emergentes en el museo La Tertulia de Cali. Imagen de elaboración propia.

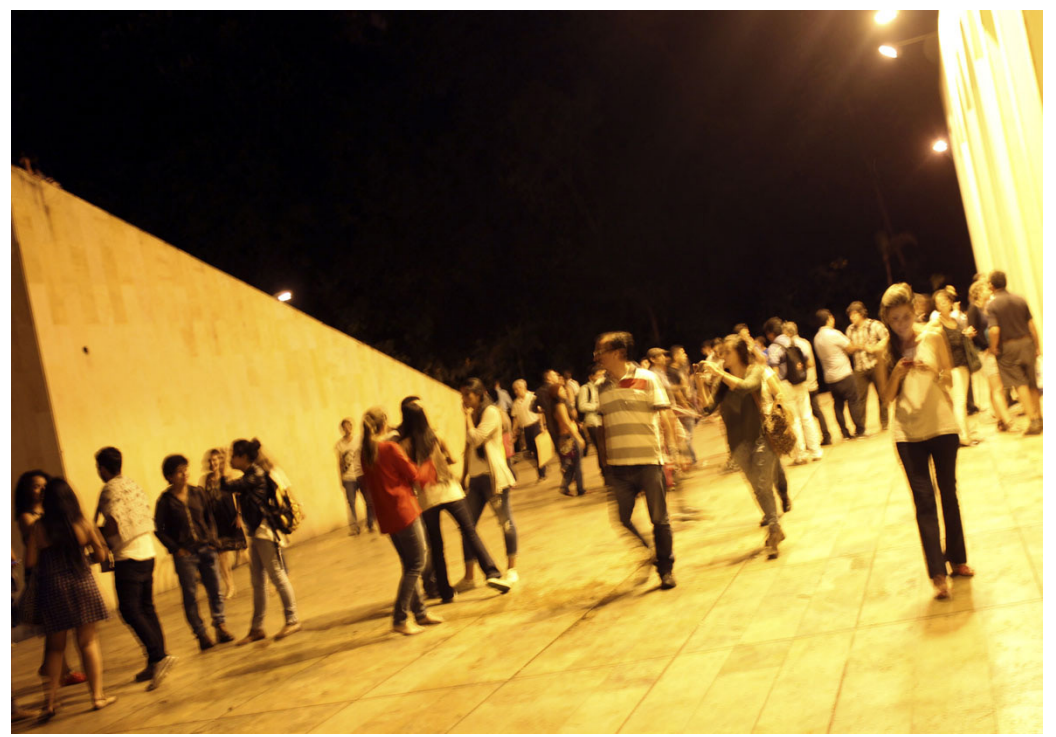

Imagen 5 - El publico como flâneur, discurriendo en el espacio de exhibición. imagen de elaboración propia

El Videomapping aborda lo espectacular y lo monumentalidad de la imagen, atravesada por las tecnologías del video proyector, los cañones de luz, el sonido y el movimiento propio del cine; con la intensión de generar en los espectadores una experiencia sensible a través de la imagen, el color, el movimiento y el reconocimiento de imágenes que evocan los espacios arquitectónicos, y en el caso en particular, se relaciona a través del espacio iconográfico del Museo La Tertulia de la ciudad Santiago de Cali - Colombia.

\section{El discurso (mecanismo) del dispositivo}

En la fase inicial de este proyecto, se indaga sobre los conceptos de espacio público y de espacio privado, en relación con la importancia del objeto encontrado y cuyas referencias están en Marcel Duchamp, en el límite 
del arte del objeto al arte del concepto; para lo cual se aborda el espacio preexistente: el Museo La Tertulia, asumiendo su fachada como espacio dispuesto a ser transformado, en principio como objeto arquitectónico a "pantalla" y objeto de apropiación del público en sus jardines y espacios abiertos. Igualmente, el dadaísmo aporta históricamente con la inclusión del fotomontaje, el collage, los ready mades, las performances; y cuyo objetivo era concebir nuevos e ilimitados espacios (campos) para el arte.

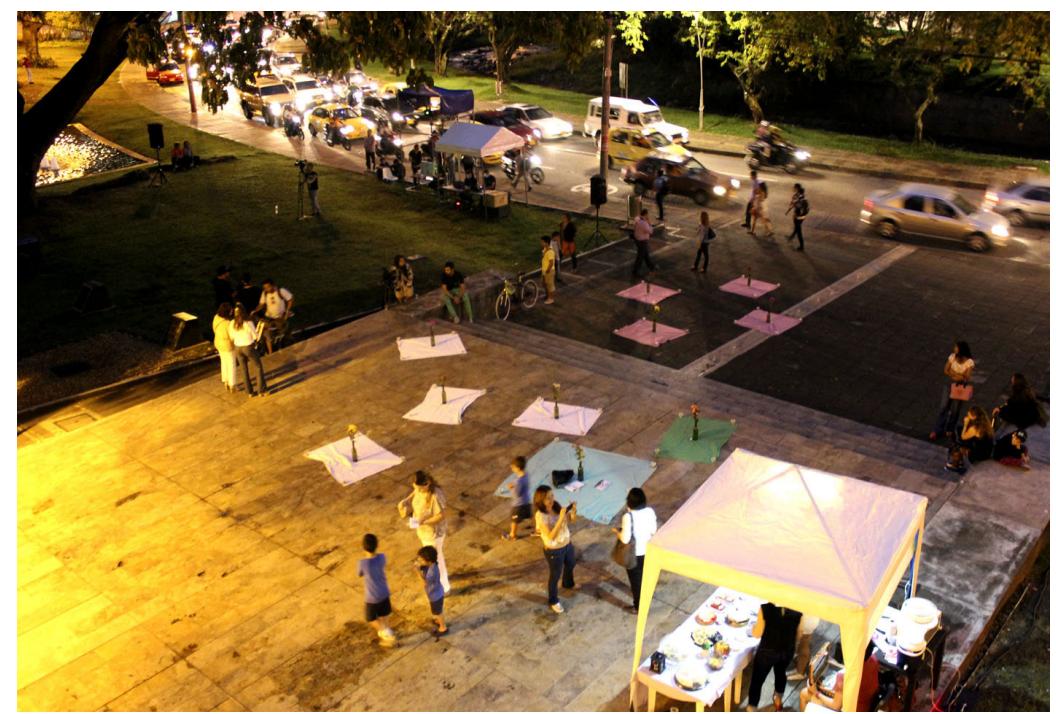

Imagen 6 - Apropiación de los jardines exteriores del museo para el evento/espectáculo/experiencia artística. Imagen de elaboración propia.

De la apropiación artística de estos elementos, surgen nuevas corrientes que entran a cuestionar el medio mismo como obra de arte, establecido por la fugacidad de la actual sociedad tecnológica. Dentro de estas nuevas tendencias se encuentran artistas visuales como Krystoff Wodiczko, quien como pionero del Videomapping, proyectó inicialmente diapositivas en espacios arquitectónicos, después incluyó video y sonido. Wodiczko utiliza su obra para hacer una crítica socio-política, y así, por medio del Mapping revela historias de los ciudadanos que proyecta en diferentes monumentos de las ciudades, para ponerlas ante el ojo público. Se puede decir que la visión del artista en el siglo XXI está más cercana a generar espacios de contacto con el público, logrando atraer a cualquier tipo de ciudadano, pues las obras logran interactuar con el espectador, desbordando el espacio circundante, en ocasiones, desde lo terrenal al espacio etéreo. Como propone Fajardo (1999):

Se impone de manera total una propuesta de efecto resemantizador de los universos estéticos. Recontextualizar, redefinir, reutilizar y deconstruir sus estructuras es el reto a que nos enfrentamos.

Bricollage e hibridación semántica deben operar para comprender en medio de estas presencias supremas, la constitución de las nuevas sensibilidades artísticas.

Algunos artistas contemporáneos han logrado sobrepasar las condiciones de espectacularidad y utilizando los recursos disponibles en el contexto, para la representación social y artística. Como el artista mexicano Rafael Lozano Hemmer, quien logra extrapolar las máximas condiciones disponibles (internet, dispositivos de tiempo real, cañones de luz robotizados de alta potencia, para obras como Alzado Vectorial del año 2000), lo mismo podría decirse del reconocido "padre del videoarte" Nam June Paik, quien disponía de la primera y 
mas avanzada cámara de video portátil de la época y acceso a los laboratorios de la tecnología de electrónica japonesa presente en su momento histórico; a diferencia del artista español Daniel Canogar, quien logra equilibrar su reflexión sobre el poder de la tecnología en el arte a través de recursos reciclados o caducos como teléfonos móviles antiguos, discos duros, etc. y elementos de alta tecnología como pantalla led flexibles y sincronización de imagen en tiempo real, presentes en la exposición Fluctuaciones del 2017 - 2018.

En Arquitecturas Emergentes, surgió la necesidad de crear imágenes monumentales para generar conflicto con el espectador y su tiempo histórico, mediante la elaboración de una serie de construcciones simbólicas de imagen en movimiento, dimensionado en una narrativa no lineal, lo cual constituyó en los lineamientos fundamentales del proyecto, elementos que corresponden a la búsqueda del concepto de Videomapping aplicado a las artes visuales. Igualmente la pieza audiovisual se creó con el fin de establecer las relaciones entre arte, ciudad, museo, espectador, espectáculo, público y tecnología. Este proyecto invita a la ciudad, al espectador caleño a desplazarse al museo; contradiciendo la afirmación de Paul Virilio (1996), donde "todo llega sin que sea necesario partir. A la llegada limitada de vehículos dinámicos, móviles, después automóviles, sucede bruscamente la llegada generalizada de las imágenes y de los sonidos en los vehículos estáticos del audiovisual" $(1996,41)$ Así, este vehículo se transforma en un "sustituto de nuestros desplazamientos físicos y prolongación de la inercia domiciliaria que verá, al final, el tiempo del sedentarismo, esta vez de un sedentarismo definitivo" (39); este proyecto invita a la ciudad, al espectador Caleño a desplazarse, a ir al museo y apropiarse de su espacio publico y revitalizar las condiciones de ciudad social, no se adapta a la inmovilidad de la pantalla sedentaria de Virilio, sino por el contrario, propone una pantalla activa, vivencial y participativa.

Se aproxima a originar nuevas cartografías simbólicas que entretejen percepciones y relaciones sobre el concepto de ciudad, paisajes emergentes, arquitectura y la interactividad del espectador frente a la obra de arte.

Adicionalmente, el concepto de espacio público y privado, proporciona bases conceptuales sólidas para la realización de esta propuesta, y permite analizar como la intervención del espacio mismo puede resinificarle. Como lo afirma Heidegger en su ensayo El Arte y el Espacio (2009), no es simplemente el lugar que ocupan o no las cosas, si no que es una disposición que se puede producir, incluso los seres son espacio, hacen espacio. Por tanto la interacción con el espacio responde a esta necesidad: crear nuevos lugares públicos dentro de los instaurados, cuestionarlos mediante la creación plástica y, sobre todo, llevar una propuesta que tradicionalmente debería ubicarse en el espacio privado y expositivo del museo, para ubicarlo en lo público con fines de generar o propiciar diálogos con el contexto y con quienes lo presencien o lo habiten.

Para el proyecto de creación, se ejecutaron pasos que permitieron, no sólo elaborar un espectáculo, sino reflexionar sobre los mecanismos de producción y su asimilación como pieza artística. La exploración se inicia con la búsqueda de espacios arquitectónicos de la ciudad con valor simbólico en el entorno del arte, finalmente se optó por confrontar la importancia del Museo La Tertulia, el cual cuenta con un gran acervo 
de obras de artistas colombianos y extranjeros y un sinnúmero de exposiciones históricas, que dan cuenta de la importancia del arte actual en Colombia. Receptor de las principales bienales de gráfica del país durante los años 80 y 90, es un Museo revitalizado, con dinámicas propias, que integra el entorno social con sus recursos expositivos, lo que permite asumir la importancia de ponerlo en diálogo con la ciudad, al Museo y al espectador en función de una imagen descomunal, de un recurso audiovisual de gran formato proyectado en su fachada y en los jardines exteriores.

A partir de allí, se indaga sobre el modelo de producción adecuado a este tipo de experiencias, se trata de comprender como llevar a cabo de forma eficiente una tarea de la cual no se tienen precedentes precisos, y de esta forma aportar a los mecanismos para la puesta en marcha de un proyecto de esta envergadura. Se realizan los bocetos conceptuales sobre la temática predominante, color, textura, fluidez de la imagen y fundamentalmente el reconocimiento del contexto local y arquitectónico a intervenir, se recrea un Story Board de secuencias animadas que permite ampliar la reflexión sobre el espacio arquitectónico seleccionado, sobre su ubicación en un recodo del rio Cali, el mas importante rio de la ciudad que lo atraviesa de oeste a este y se convierte en el paisaje natural-urbano de mayor reconocimiento en la ciudad, igualmente, las secuencias dibujadas permiten considerar otros aspectos de relevancia en la región como la importancia que el agua y el Océano Pacífico ejercen en la ciudad y la región; igualmente, el museo como contenedor de piezas artísticas se convierte en el motivo principal de la propuesta, asumiendo de forma gráfica algunas de las piezas más relevantes que se encuentran en su archivo.

Gracias a este desarrollo inicial, fue posible continuar con la búsqueda de caminos para el desarrollo del proyecto, donde se eligió un modelo de producción audiovisual como mecanismo de creación, con los procesos de preproducción, producción y postproducción, además de aplicar recursos de los procesos de animación, integrado a componentes del espectáculo público. En consecuencia, se utilizaron en diferentes etapas, los modelos de animación digital en función de la imagen como: motion graphics, rotoscpia, dibujo animado, animación por recortes, cuadro a cuadro y time lapse; se concluyó un proyecto audiovisual de 14 minutos. Con este insumo de herramientas tecnológicas, se realiza el proceso de imagen en movimiento. Para las diversas pruebas de función se ha requerido la construcción de una maqueta a escala de la fachada del Museo, en la cual continuamente se realizaron las pruebas y se tomaron decisiones de imagen, mapeando las estructuras físicas y la proyección sobre ellas. Finalmente, la preparación y la puesta en marcha de la proyección en el espacio público, requirieron de mecanismos propios de exhibición en tiempo real con recursos físicos y tecnológicos como plantas de energía, proyectores de alta potencia, hardware y software computacional de alta capacidad gráfica. 


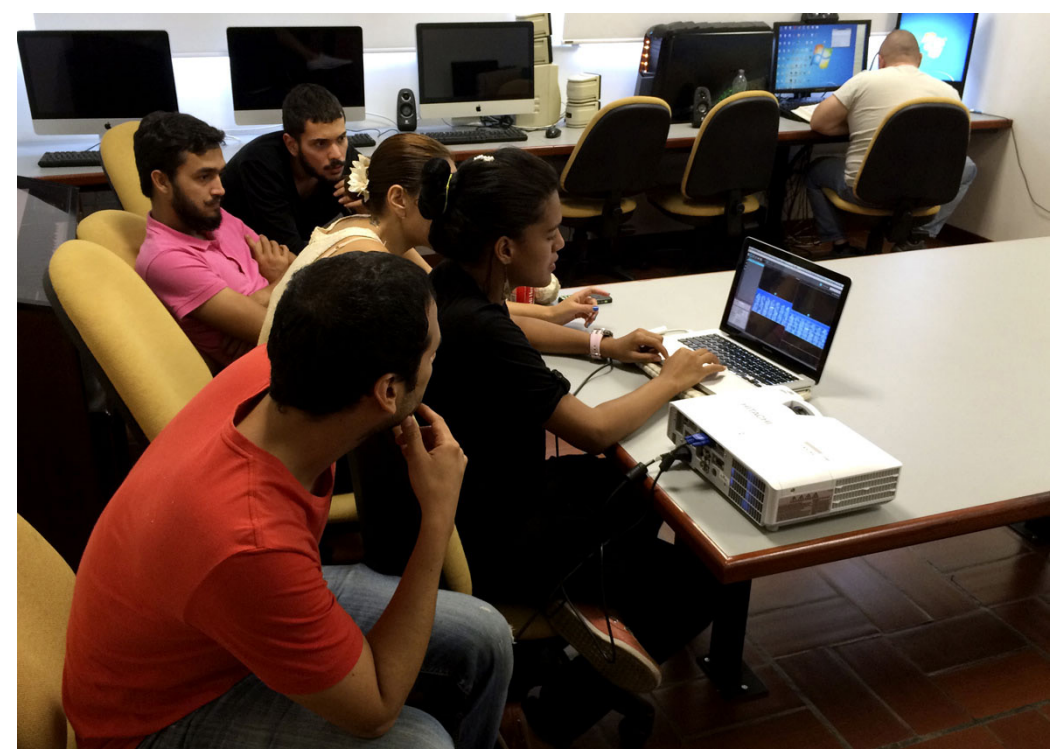

Imagen 7 - Adaptación del modelo de producción técnica y trabajo en equipo como recurso fundamental del proyecto. Imagen de elaboración propia.

En el desarrollo de esta investigación se estructuraron recursos de mediación conceptual, que dieron cuenta de algunas categorías en la elaboración del Mappin aplicado a las Arte Visuales: software, espacio público, espectador, monumentalidad, arquitectura, arte efímero, interactividad y producción audiovisual. Lo que puso en evidencia una estrecha relación entre arte, ciencia, tecnología y sociedad. Al respecto, Peter Weibel (2008) menciona:

El arte y la ciencia se deben comparar en función de sus metodologías, sus paralelismos y sus diferencias. La ciencia no se ve influenciada por el arte en el nivel de la producción, sino en el de los métodos. Porque cada vez que la ciencia desarrolla una tendencia en la que sus métodos se vuelven demasiados autoritarios o dogmáticos, recurre al arte y a su metodología, que es una pluralidad de métodos. El arte se nutre de la tolerancia y la diversidad de los métodos. (p.19).

La pieza Arquitecturas Emergentes propone una impresión de la imagen a gran escala, generando una experiencia estética en los espectadores a través de la imagen digital y la apropiación a los conceptos como: ciudad, museo, historia y público; logrando una estrecha relación entre la obra y el espectador; y el sin número de interpretaciones que se puede lograr en función de lo que puede suscitar la obra, lo que permite que las posibilidades de observación, percepción y reflexión sea infinita, asumiendo así, la elaboración de nuevas narrativas y realidades evocadas por la imagen en un entorno local determinado, abarcando ámbitos tecnológicos, técnicos, históricos, estilísticos y estéticos, lo que provoca desde el arte una tecnología humanizada, híbrida y cambiante al servicio del artista y del espectador, a lo que alude nuevamente Weibel (2008) al afirmar que:

Un arte tecnológico, el cual es el reflejo ideológico de una sociedad existente y del deseo de cambiar a una sociedad industrial, basada en las máquinas o a una sociedad postindustrial basada en los medios. Por lo tanto la tecnología y sus avances devienen de los factores productivos de una sociedad. 


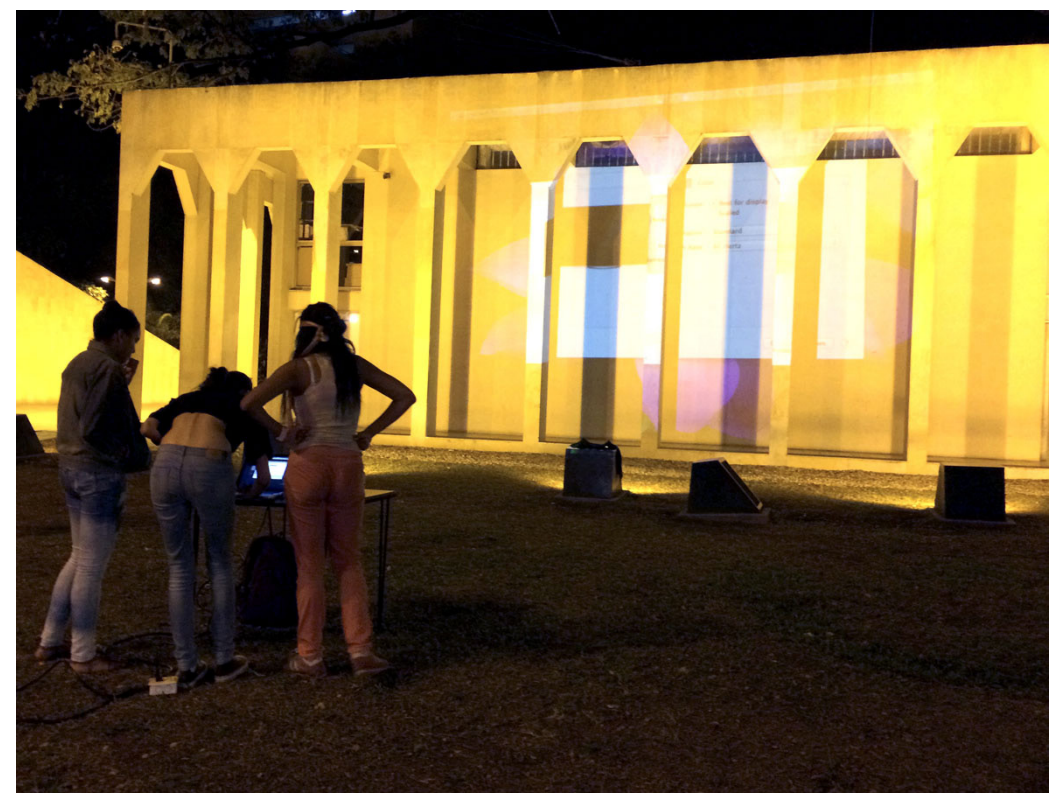

Imagen 8 - Pruebas de función en el espacio físico del museo La Tertulia. Imagen de elaboración propia.

\section{Conclusiones}

Desde sus inicios el Videomapping ha encontrado su aplicación prolífica en eventos publicitarios y espectáculos que no van más allá de la imagen monumental como herramienta para generar impacto en el consumidor. Pero las posibilidades que abre el uso de estas técnicas para los nuevos espacios artísticos aparece casi como una predicción de "el arte del futuro". Se debe tener en cuenta el terreno incipiente de las artes y los nuevos medios en Colombia, especialmente en Cali, en donde empieza a hacerse evidente la necesidad de este tipo de proyectos, para propiciar una escena del arte proactiva los nuevos medios y recursos de creación, y generar nuevas sinergias entre los diferentes espacios de la sociedad y el arte.

Es una necesidad de actualización y conexión con la contemporaneidad que representa un sinfín de herramientas tecnológicas, electrónicas e informáticas, permiten avanzar en la fundamentación conceptual en las artes electrónicas, diferenciada de otras áreas, justificando este proyecto gracias a la adquisición de conocimientos nuevos y permitiendo conceptualizar desde la experiencia local, trascendiendo en el entorno social. Los nuevos medios contienen tal elocuencia sobre diferentes conceptos actuales y completamente vigentes, como la reflexión de la contemporaneidad efímera. La evolución de las prácticas artísticas permite abordar los constantes problemas del arte desde perspectivas novedosas: la memoria, el espacio, la imagen, el tiempo. Por tanto es completamente pertinente utilizar las relaciones arte / tecnología /sociedad como un insumo para ilustrar los procesos de creación actuales en esta llamada "era de la información", que convierte al mundo en una aldea global, tejida entre avances tecnológicos e internet, y ello es una novedad que debe se representada artísticamente para empezar a construir historia. El estado del arte de lo que es la sociedad de hoy, constituyendo un proceso constante de evolución y construcción conceptual, mediante diálogos interdisciplinares, respondiendo a los intereses del mundo del arte contemporáneo, incursionando 
en la exploración de aplicativos digitales, para consolidar un puente que articule nuevas formas de producción artística, con mecanismos de producción tecnológica, implicando la transformación del sentido de autor, aceptando la participación de múltiples creadores participativos, lo que Fajardo (1999) aborda como:

Una amalgama tan grande de posibilidades, lo computacional va haciendo desaparecer el concepto moderno del Yo Creador individual, transformando también la relación espectadorarte, pues éste puede a la vez crear la obra, programarla, desfigurarla a su antojo. Con ello desaparece la era de la interpretación y se entra a la era de la programación, subordinando el lenguaje al cálculo, a los modelos numéricos proteiformes. (Fajardo, 1999)

En este sentido, Arquitecturas Emergentes a involucrado la participación creativa y técnica de mas de 20 personas, asumiendo roles específicos con un fin común, animadores, programadores, técnicos, eléctricos, diseñadores, comunicadores, fotógrafos, etc. apoyando la idea del autor colectivo, abriendo lo que Piscitelli denomina nuevas "ventanas utópicas" (1995), que permite al arte contemporáneo realizar collages electrónicos, mesclando sonidos, textos, imágenes, movimiento, elaborando una cibermirada, o visiones digitales (ibid)

Finalmente, es posible afirmar que el videomapping puede ser asumido como recurso de las artes, pero siempre mediada por cuestionamientos propios de los nuevos medios de representación del arte, dejando una serie de preguntas hacia el valor y el aporte de este tipo de arte digital hoy en día: ¿Será que nos estamos convirtiendo en seres que necesitamos de lo público para manifestar o responder a un serie de inquietudes? O ¿será más bien, la necesidad de vivenciar el arte en estos espacios lo que nos da la vida? ¿Será que esto podría servir para canalizar nuestros intereses, vivencias, etc.? O, simplemente, ¿es la necesidad de interactuar y acercarse al otro?

Vinculo externo al video del evento en Santiago de Cali, el 31 de Enero de 2015: https://vimeo. com/140681146

\section{Referencias}

- $\quad$ Bauman, Z. (2005), Modernidad líquida, Argentina: Fondo de Cultura Económica:

- $\quad$ Bourdieu, P. (1972). Esquisse d'une théorie de la pratique, Genéve: Ed. Droz.

- $\quad$ Fajardo, C. (1999). Hacia una estética de la cibercultura. Espéculo. Revista de estudios literarios. Numero 10. Universidad Complutense de Madrid

- Gómez, A. (2004). Ciudadanos como cyborgs. En: Kepes. ed: Centro Editorial Universidad de Caldas

- $\quad$ Gimenez, G. (1997). La sociología de Pierre Bourdieu. Instituto de Investigaciones Sociales de la UNAM, 1-23. Recuperado de http://www.paginasprodigy.com/peimber/BOURDIEU.pdf

- $\quad$ Gubern, R. (1996). Del bisonte a la realidad virtual, la escena y el laberinto. Barcelona: Anagrama.

- Gunning, T. (1983). The Cinema of Attractions: Early Film, Its Spectator, and the Avand-Garde. Wide Angle.

- $\quad$ Heidegger, M. (2009). El arte y el espacio. Ed. HERDER 
- Hernández, F. (1994). Manual de museología. Madrid; Sintesis.

- Jiménez, A. (2010). El cine digital como Caballo de Troya. Bogotá Fundación Gilberto Álzate Avendaño

- $\quad$ Malraux, A. (1956). El museo imaginario en Las voces del silencio. Buenos Aires, Emecé.

- $\quad$ Oubiña, D. (2009). Una juguetería filosófica. Buenos Aires: Ediciones Manantial

- $\quad$ Piscitelli, A. Las ciberculturas. En la era de las máquinas inteligentes. Buenos Aires: Paidós,1995.

- $\quad$ Rodríguez, L. (2011) Videografia y arte: indagaciones sobre la imagen en movimiento. análisis de practicas videográficas que investigan sobre la imagen. Universidad Jaume I. Servicio de comunicación y publicaciones,

- $\quad$ Satué, E. (2001). El paisaje comercial de la ciudad. Barcelona, Ed. Paidós.

- $\quad$ Trujillo, P. (2012). Siglo XXI: Sociedad multimedial, sociedad de pantallas. Revista Educación y pensamiento.

V. 19

- Virilio, P. El arte del motor. Aceleración y realidad virtual. Buenos Aires: Ed. Manantial, 1996

- $\quad$ Weibel, P. (2008). Razones para la BIACS3. Biacs, (3), p.19.

- Wigal, D. (2011). Pollock. Ed Parkstone International

\section{Imágenes}

Imagen 1 - Procesos Iniciales en la conceptualización y creación del videomapping Arquitecturas Emergentes. Elaboración propia 6

Imagen 2 - Reconocimiento de la diversidad cultural y religiosa. Imagen de captura de movimiento para técnica de rotoscopia. Imagen de elaboración propia. $\quad 8$

Imagen 3 - Pruebas de función de la imagen proyectada sobre maqueta a escala de la fachada del museo La Tertulia. Imagen de Elaboración propia. 9

Imagen 4 - Publico durante la proyección del videomapping Arquitecturas Emergentes en el museo La Tertulia de Cali. Imagen de elaboración propia. 10

Imagen 5 - El publico como flâneur, discurriendo en el espacio de exhibición. imagen de elaboración propia 11

Imagen 6 - Apropiación de los jardines exteriores del museo para el evento/espectáculo/experiencia artística. Imagen de elaboración propia. 12

Imagen 7 - Adaptación del modelo de producción técnica y trabajo en equipo como recurso fundamental del proyecto. Imagen de elaboración propia. 15

Imagen 8 - Pruebas de función en el espacio físico del museo La Tertulia. Imagen de elaboración propia. 16 